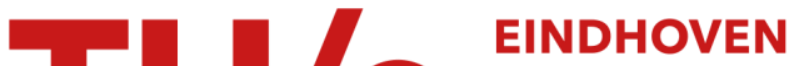 UNIVERSITY OF TECHNOLOGY
}

\section{Improved methods of estimating monomer reactivity ratios in copolymerization by considering experimental errors in both variables}

Citation for published version (APA):

Meer, van der, R., Linssen, H. N., \& German, A. L. (1978). Improved methods of estimating monomer reactivity ratios in copolymerization by considering experimental errors in both variables. Journal of Polymer Science, Polymer Chemistry Edition, 16(11), 2915-2930. https://doi.org/10.1002/pol.1978.170161117

DOI:

10.1002/pol.1978.170161117

Document status and date:

Published: 01/01/1978

Document Version:

Publisher's PDF, also known as Version of Record (includes final page, issue and volume numbers)

\section{Please check the document version of this publication:}

- A submitted manuscript is the version of the article upon submission and before peer-review. There can be important differences between the submitted version and the official published version of record. People interested in the research are advised to contact the author for the final version of the publication, or visit the $\mathrm{DOI}$ to the publisher's website.

- The final author version and the galley proof are versions of the publication after peer review.

- The final published version features the final layout of the paper including the volume, issue and page numbers.

Link to publication

\footnotetext{
General rights

- You may freely distribute the URL identifying the publication in the public portal. follow below link for the End User Agreement:

www.tue.nl/taverne

Take down policy

If you believe that this document breaches copyright please contact us at:

openaccess@tue.nl

providing details and we will investigate your claim.
}

Copyright and moral rights for the publications made accessible in the public portal are retained by the authors and/or other copyright owners and it is a condition of accessing publications that users recognise and abide by the legal requirements associated with these rights.

- Users may download and print one copy of any publication from the public portal for the purpose of private study or research.

- You may not further distribute the material or use it for any profit-making activity or commercial gain

If the publication is distributed under the terms of Article 25fa of the Dutch Copyright Act, indicated by the "Taverne" license above, please 


\title{
Improved Methods of Estimating Monomer Reactivity Ratios in Copolymerization by Considering Experimental Errors in Both Variables
}

\author{
R. VAN DER MEER, H. N. LINSSEN,* and A. L. GERMAN, Laboratory of \\ Polymer Technology, Eindhoven University of Technology, Eindhoven, The \\ Netherlands
}

\begin{abstract}
Synopsis
Existing methods of calculating monomer reactivity ratios in copolymerization are reviewed briefly, evaluated, and classified according to their mathematical and computational similarities. More attention is paid to procedures based on the integrated copolymer equation with which calculation of $r$ values is performed most often by electronic computer. Unfortunately, until now all procedures have shown shortcomings because the real-error strueture of the observations has not been taken into account. A new algorithm that does account correctly for measurement errors in both variables is described. A computational method is illustrated for copolymerization data obtained from quantitative gas chromatographic analysis of the monomer feed throughout the reaction. It is shown that the actual error structure of the variables corresponds to the assumed error structure. Reliability of the estimates is substantially increased, compared with the existing methods. Standard deviations of the monomer reactivity ratios are given and appear to be in good agreement with reality.
\end{abstract}

\section{INTRODUCTION}

Since 1944, when the simple copolymer equation was derived by Alfrey and Goldfinger ${ }^{1}$ and Mayo and Lewis, ${ }^{2}$ two developments in copolymerization kinetics, namely, computerized calculation and gas-liquid chromatography (GLC), have governed progress in this science. By the use of electronic computers more complicated and extended calculations ${ }^{3,4}$ for the determination of monomer reactivity ratios became possible, but the introduction of gas chromatographic analysis (GLC) of monomer feed composition during a copolymerization reaction $^{4-6}$ was an important step forward, for it made the laborious and inaccurate copolymer analysis redundant.

Two recent reviews $s^{7,8}$ on the science of the determination of monomer reactivity ratios clarified most of the existing misunderstandings concerning the accuracy of calculation procedures. Unfortunately, neither review paid much attention to those procedures based on the integrated copolymer equation ${ }^{2,9}$ nor on experimental techniques based on GLC. 4,5 Nevertheless, it became clear that progress in the fundamental aspects of radical (co)polymerization theory will require highly precise monomer reactivity ratios.

This article aims at comparing the existing experimental techniques and giving a concise survey of the imperfections of all known calculation procedures before presenting a novel and highly accurate method of computing monomer reactivity ratios. This procedure, based on the integrated copolymer equation, considers

\footnotetext{
*Present address: Department of Mathematics, Eindhoven University of Technology, Eindhoven, The Netherlands.
} 
experimental errors in both measured variables, whereas, as a typical example, an earlier procedure reported by German and Heikens ${ }^{4}$ considered measurement errors in only one of the variables.

\section{CRITICAL SURVEY}

\section{Experimental Techniques}

At this time two basically different experimental techniques can be distinguished for the determination of monomer reactivity ratios:

(1) Compositional analysis of initial feed and copolymer formed.

(2) Monomer feed compositional analysis.

Method 1, the conventional technique, is still used by many investigators, although the low conversion requirement induces many problems, and copolymer compositional analysis is often inaccurate and accompanied by many difficulties:

(a) Copolymer isolation and purification is laborious and frequently accompanied by fractionation with respect to composition.

(b) Almost all binary combinations need different experimental techniques (IR, NMR-spectroscopy, elemental analysis, thermogravimetric analysis, radiotracer assay, and so on).

(c) Experimental errors are unknown because different techniques almost unvariably lead to different results for the same sample.

Method 2 became possible by the introduction of gas-liquid chromatographic analysis $^{4,5}$ and lacks the drawbacks of the conventional method (1). Moreover, method 2 offers some additional advantages:

(a) Gaseous monomers can be used more easily.

(b) Samples can be taken throughout the copolymerization reaction (sequential sampling technique). ${ }^{4}$

\section{Differential and Integral Copolymer Equation}

The most popular mathematical model for the description of copolymer kinetics is the well-known, simple Alfrey-Mayo equation ${ }^{1,2}$ :

$$
\frac{d\left[M_{1}\right]}{d\left[M_{2}\right]}=\frac{\left(\left[M_{1}\right] /\left[M_{2}\right]\right) \cdot r_{1}+1}{\left(\left[M_{2}\right] /\left[M_{1}\right]\right) \cdot r_{2}+1}
$$

where $\frac{d\left[M_{1}\right]}{d\left[M_{2}\right]}=\begin{gathered}\text { the ratio of the instantaneous rates of consumption of the } \\ \text { monomers by chain propagation, }\end{gathered}$

$$
\begin{gathered}
\frac{\left[M_{1}\right]}{\left[M_{2}\right]}=q=\begin{array}{r}
\text { is the ratio of the molar concentrations of monomer } M_{1} \text { and } M_{2}, \\
\text { respectively, }
\end{array} \\
r_{1}, r_{2}=\text { the monomer reactivity ratios, defined as usual. }
\end{gathered}
$$

Thus the differential copolymer equation [eq. (1)] describes the composition of the instantaneously formed copolymer as a function of the relevant monomer feed composition only. Therefore it is obvious that in copolymerization experiments, in which calculation procedures of monomer reactivity ratios are based on eq. (1), the conversion to copolymer has to be kept as small as possible.

Integration $^{2}$ of eq. (1) yields an exact relationship between the changing monomer feed ratio $(q)$ and the degree of conversion, based on $M_{2}\left(f_{2}\right)$ : 


$$
f_{2}=100 \cdot\left[1-\left(\frac{q}{q_{0}}\right)^{-x_{2}-1}\left(\frac{x_{2} q-x_{1}}{x_{2} q_{0}-x_{1}}\right)^{x_{1}+x_{2}+1}\right]
$$

where $f_{2}=100\left(1-\frac{\left[M_{2}\right]}{\left[M_{2}\right]_{0}}\right) \%$, degree of conversion of $M_{2}$,

$$
\begin{aligned}
& x_{1}=\frac{1}{r_{1}-1}, \\
& x_{2}=\frac{1}{r_{2}-1},
\end{aligned}
$$

and the subscript zero indicates conditions at zero conversion.

Most copolymerization reactions, regardless of the experimental technique applied, will inevitably show a drift in the molar feed ratio as the degree of conversion increases. For this reason the integrated form [eq. (2)] should be preferred over the differential form of the copolymer equation in reliable calculation procedures for reactivity ratios. Furthermore, it should be emphasized that nonstationary reaction conditions occurring at the start of copolymerization demand high-conversion experiments.

In the next section various calculation procedures based on the differential and integral copolymer equations, are summarized, classified, and separately discussed. More attention is paid to procedures based on the integrated copolymer equation [eq. (2)] because they have been almost entirely neglected in recent reviews. ${ }^{7,8}$

\section{Existing Calculation Procedures}

Tidwell and Mortimer ${ }^{10}$ distinguished four different procedures for the calculation of the monomer reactivity ratios in copolymerization, namely, approximation, linearization, intersection, and curve fitting. Shortly after Schaefer ${ }^{11}$ introduced the spectral procedure, and other new approaches and important improvements to existing procedures were published later on. In Table I all calculation procedures known to us have been classified.

\section{Procedures Based on the Differential Copolymer Equation}

The approximation $D$ procedure, probably first mentioned by Tidwell and Mortimer, ${ }^{10}$ depends on the fact that at extremely low concentrations of either monomer (e.g., $M_{2}$ ) the consumption of both monomers occurs almost entirely by chain-end radicals $P_{1}^{*}$, which leads to

$$
\frac{d\left[M_{1}\right]}{d\left[M_{2}\right]}=r_{1} \cdot \frac{\left[M_{1}\right]}{\left[M_{2}\right]}
$$

This method requires extremely sensitive analytical techniques, and, in addition, it is implicitly assumed that the experiments can be described by the usual Alfrey-Mayo model. ${ }^{1,2}$ Any deviation from this model will not show up.

In the intersection $D^{2}$ and all linearization procedures ${ }^{13-15}$ transformation of the original differential copolymer equation [eq. (1)] leads to transformation(s) of the original error structure of the measured variables. ${ }^{9,18}$ The transformed error no longer has an expected value of zero so that essential information will have been lost and only approximate $r$ values will be found.9,18 Proposed im- 


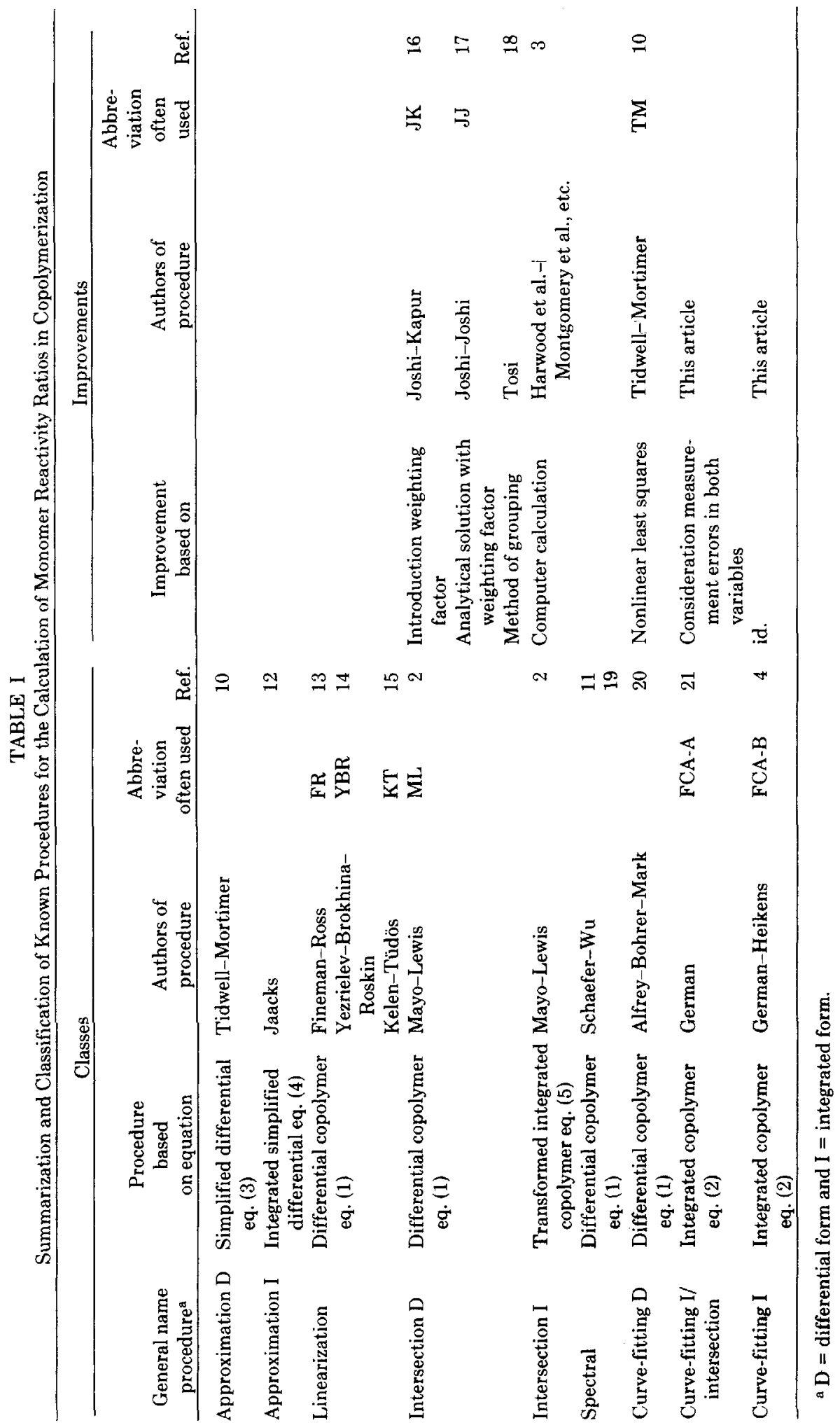


provements, ${ }^{16-18}$ based on a more objective calculation of the center of gravity of the intersection points in the intersection $\mathrm{D}$ procedure, therefore will never lead to reliable $r$ values. ${ }^{17}$

The spectral procedure ${ }^{11,19}$ is based on measurements of the fractions of triads in a copolymer and requires high-resolution nuclear magnetic resonance (NMR). This method, however, is not universally applicable to all binary combinations and leads to inaccurate $r$ values because of considerable measurement errors in the fraction of triads.

Originally, the curve-fitting $D$ procedure ${ }^{20}$ was a method of trial and error for finding the best fitting curve in a graph of the initial mole fraction in the monomer feed $\left\{\left[M_{1}\right] /\left(\left[M_{1}\right]+\left[M_{2}\right]\right)\right\}$ versus the mean mole fraction present in the copolymer $\left\{d\left[M_{1}\right] /\left(d\left[M_{1}\right]+d\left[M_{2}\right]\right)\right\}$. Tidwell and Mortimer ${ }^{10}$ improved and facilitated this procedure by using a nonlinear least-squares computer program with $d\left[M_{1}\right] /\left(d\left[M_{1}\right]+d\left[M_{2}\right]\right)$ as the dependent variable.

Many investigators already recognized that for all calculation procedures based on eq. (1) the use of the mean monomer feed composition during the copolymerization reaction will invariably provide a better approximation than the initial monomer feed composition.

\section{Procedures Based on the Integral Copolymer Equation}

In the approximation I procedure ${ }^{12}$ the simplified differential copolymer equation [eq. (3)] has been integrated:

$$
\log \frac{\left[M_{1}\right]}{\left[M_{1}\right]_{0}}=r_{1} \cdot \log \frac{\left[M_{2}\right]}{\left[M_{2}\right]_{0}}
$$

where the subscript zero again denotes initial conditions. Equation (4) is valid up to high conversions to copolymer, provided the excess of $M_{1}$ remains large enough throughout the copolymerization. The limitations mentioned for the approximation D procedure, however, are also encountered in this procedure.

In the intersection I procedure ${ }^{2}$ the integrated copolymer equation [eq. (2)] has been transformed into an expression for $r_{2}$ :

$$
r_{2}=\frac{\log \left[\left(100-f_{1}\right) / 100\right]+(1 / p) \log A}{\log \left[\left(100-f_{2}\right) / 100\right]-\log A}
$$

where $f_{1}=100 \cdot\left(1-\frac{\left[M_{1}\right]}{\left[M_{1}\right]_{0}}\right) \%$, the degree of conversion of $M_{1}$,

$$
\begin{aligned}
A & =\frac{1-p q}{1-p q_{0}}, \\
p & =\frac{1-r_{1}}{1-r_{2}} .
\end{aligned}
$$

Calculation of monomer reactivity ratios from eq. (5) can be performed by determining the almost straight lines in an $r_{1}-r_{2}$ diagram for each experiment separately. Next, the center of gravity of the intersection points of all these lines can be calculated.

Determination of a straight line can be achieved by choosing suitable values for $p$; then corresponding values for $r_{2}$ and $r_{1}$ can be solved from eqs. (5) and (6). Because these calculations are time consuming, all investigators who use this 
technique resort to computer calculations. ${ }^{3}$ Because the linearization of the model function introduces unknown errors, the center of gravity of many intersecting lines can be defined in a number of ways, as indicated by the great diversity of improvements proposed (see Table I) for the intersection D procedure. Basically these improvements differ only in the weighting factor assigned to a particular line. A weighting that considers the real-error structure of the variables seems to be difficult to achieve in this calculation procedure.

In the curve-fitting I procedure reported by German and Heikens ${ }^{4}$ each experiment is allowed to contain more than two observations because a nonlinear least-squares fitting is applied to eq. (2), which can be formulated as a minimization of the sum of squares of the difference of the observed degree of conversion $\left(F_{2 j i}\right)$ and the calculated degree of conversion, for all observations:

$$
\text { sum of squares }=\sum_{j=1}^{n} \sum_{i=1}^{g_{j}}\left[F_{2 j i}-H\left(r_{1}, r_{2}, q_{0 j}, Q_{j i}\right)\right]^{2}
$$

where $H\left(r_{1}, r_{2}, q_{0 j}, Q_{j i}\right)=$ the right-hand expression in eq. (2),

$j=1, \ldots, n=$ the number of kinetic experiments,

$i=1, \ldots, g_{j}=$ the number of observations of each experiment,

$F_{2 j i}, Q_{j i}=$ the observed degree of conversion and the molar feed ratio, successively,

$r_{1}, r_{2}$ and $q_{0 j}(j=1, \ldots, n)=$ the parameters to be estimated.

This curve-fitting I procedure, earlier referred to as "Feed Compositional Analysis-B" (FCA-B), ,21 leads immediately to the desired $(n+2)$ parameters after a number of iterations. The total number of observations allowed is dependent on computer memory only.

The FCA-A procedure reported by German ${ }^{21}$ is also based on a minimization [eq. (7)], but for each experiment separately (i.e., $j$ is fixed), where two parameters $r_{2}$ and $q_{0}$ have to be estimated for arbitrarily chosen values of $r_{1}$. In an $r_{1}-r_{2}$ diagram, then, an almost straight line is obtained for each experiment. The center of gravity yields only approximate values for the monomer reactivity ratios because the weight of each line is different and mainly dependent on the number of observations of the pertaining experiment. Procedure A, however, is valuable for a rough estimation of the $r$ values, which may be used as starting values for the calculation of more accurate monomer reactivity ratios by procedure $B$. Strongly deviating experiments can easily be detected by procedure A, while in addition, it offers the possibility of a simple test ${ }^{21,22}$ of the validity of the Alfrey-Mayo scheme. Procedure A, in fact, may be regarded as a combination of the curve-fitting I and intersection I procedures. In both $A$ and $B$ variants of the curve-fitting I procedure it has been assumed implicitly that only one of the measured variables, in this case $F_{2 j i}$, contains an experimental error, although both $Q_{j i}$ and $F_{2 j i}$ result from the same set of GLC observations. In the next section it is explained comprehensively why the conditions for the application of the simple nonlinear least-squares procedure are not met for the curve-fitting procedures available. As an example, the FCA, an earlier curve-fitting I procedure reported by German and Heikens, ${ }^{4,21}$ is discussed. 


\section{Conditions for Application of the Method of Nonlinear Least Squares}

The existing methods of nonlinear least squares are most suitable when the following conditions are met: (1) the errors in the dependent or response variable are random, statistically independent from observation to observation with constant variance. ${ }^{7,9,10}$ This method is equivalent to the maximum-likelihood method if the error distribution of the observations is normal ${ }^{23}$; (2) the independent variable contains no measurement error ${ }^{8}$; (3) the copolymerization model must be consistent with the experimental data.

Many mathematical models developed for chemical and physical processes contain two variables, one of which, the dependent variable, usually contains an experimental measurement error; the other, the independent variable, is assumed to be errorless. In many other cases this simplification is not justified, although implicitly assumed to hold in order to allow nonlinear estimation. $\mathrm{Joshi}^{8}$ first recognized that the second requirement is not always fulfilled in the existing procedures for the calculation of monomer reactivity ratios. The curve-fitting $D$ procedure, ${ }^{10}$ for example, may suffer from the fact that the independent variable, the initial molar feed composition, in this procedure inevitably has a measurement error. Therefore Joshi ${ }^{8}$ proposed to minimize the square of the normal distance $(d)$, instead of the vertical distance $(b)$, as shown in Figure 1. Also, in both FCA procedures ${ }^{4,21}$ the independent variable $(q)$ has been assumed to be errorless. This article shows that in certain cases this simplification may lead to significant errors in the estimated parameters. When $q$ changes very slowly with the degree of conversion, it can be easily recognized that a small error in $q$ will lead to a large difference between the observed and the calculated degree of conversion [distance $a$ in Fig. 2] and consequently highly inaccurate reactivity ratios.

Before presenting the general features of a novel algorithm, which considers the real-error structure of the variables appearing in the FCA procedures, ${ }^{4,21}$ a more detailed analysis of the error structure of $Q$ and $F_{2}$ is necessary.

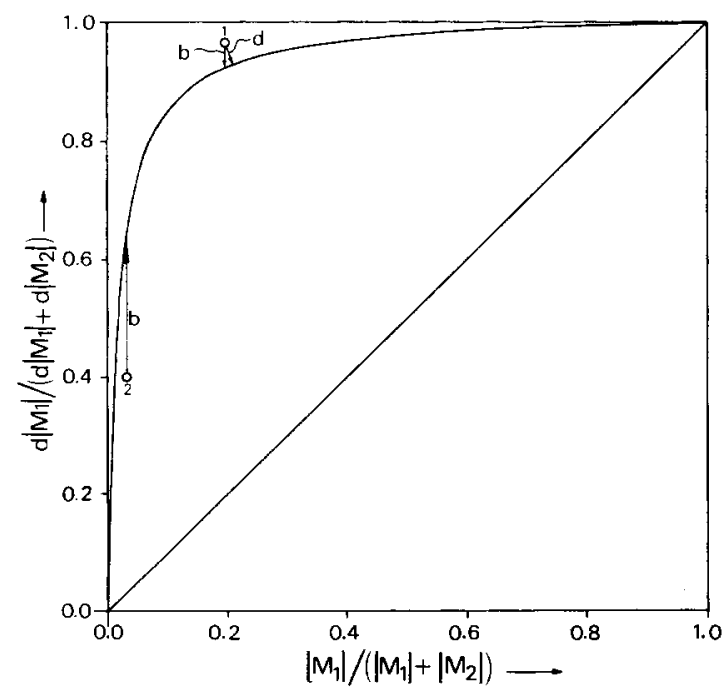

Fig. 1. Initial molar feed composition $\left[M_{1}\right] /\left(\left[M_{1}\right]+\left[M_{2}\right]\right)$ versus the instantaneous molar copolymer composition $d\left[M_{1}\right] /\left(d\left[M_{1}\right]+d\left[M_{2}\right]\right)$ for an arbitrarily chosen monomer combination with $r_{1}=50$ and $r_{2}=0.02$ and two devised observations. 


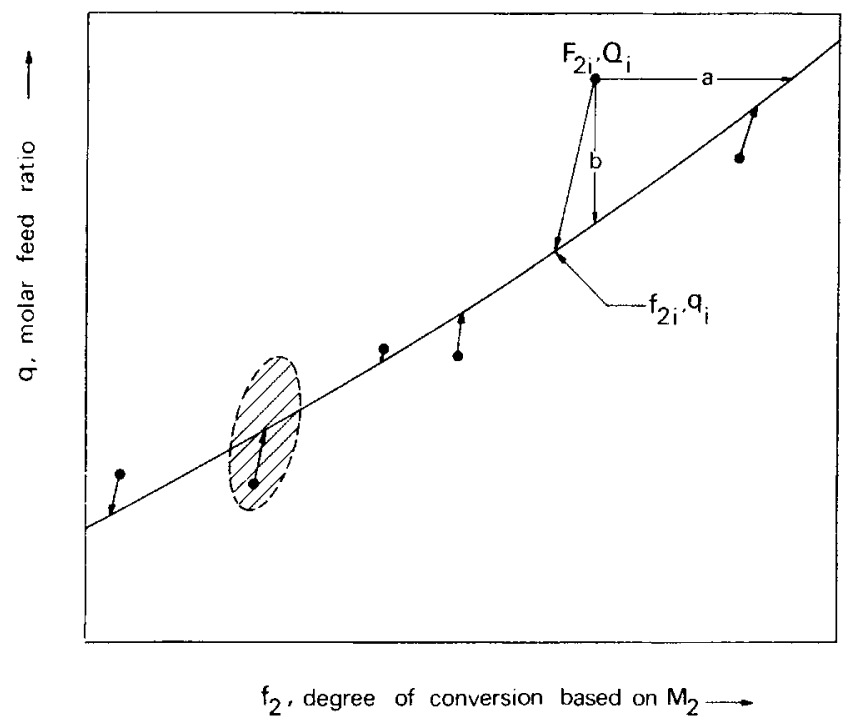

Fig. 2. Part of a plot of the monomer feed ratio $(q)$ versus the degree of conversion $\left(f_{2}\right)$ showing, for example, a real density contour (hatched) of one observation; the other features are discussed in the text.

\section{IMPROVED CALCULATION PROCEDURE}

\section{Error Structure of the Variables}

The GLC technique, described by German and Heikens ${ }^{4,21,24}$ for the sequential analysis of a copolymerizing reaction mixture, yields direct information about the instantaneous monomer feed composition in terms of three peak areas: $A_{0}$ = observed area of solvent, $A_{1}=$ observed area of monomer $M_{1}$, and $A_{2}=$ observed area of monomer $M_{2}$. The observational errors in the peak areas are assumed to be independent with standard deviations:

$$
\sigma\left(A_{k}\right):=\lambda_{k} \alpha_{k} \sigma \quad k=0,1,2
$$

where $\alpha_{k}$ denotes the true value of the observed area and $\sigma$ is a common, possibly unknown, scale factor. Next, $\lambda_{k}$ is explained. Denoting

leads to

$$
\Delta A_{k}:=\frac{A_{k}}{\alpha_{k}}-1
$$

$$
\sigma\left(\Delta A_{k}\right)=\lambda_{k} \sigma \quad k=0,1,2
$$

This means that the relative errors in $A_{0}$ and $A_{1}$ are allowed to differ a known factor of $\lambda_{0} / \lambda_{2}$ and $\lambda_{1} / \lambda_{2}$, respectively, from the relative error in $A_{2}$. The variables $q\left(=\right.$ monomer feed ratio) and $f_{2}\left(=\right.$ degree of conversion based on $\left.M_{2}\right)$ are related by eq. (2):

$$
f_{2}=H(\beta, q)
$$

where $\beta$ is a vector of the unknown parameters to be estimated [cf. eq. (7)]; $f_{2}$ and $q$ are unknown quantities that may, however, be observed. The observations of $f_{2}$ and $q$ are denoted by $F_{2}$ and $Q$ and defined as

$$
F_{2}:=100 \cdot\left\{1-\frac{A_{2}}{A_{0}} \cdot c_{f}\right\} \%
$$


and

$$
Q:=\frac{A_{1}}{A_{2}} \cdot c_{q}
$$

where $c_{q}$ is a system constant and $c_{f}$ is a constant for the starting level, both of which are assumed to be known without experimental error. If no measurement errors were present, then $F_{2}$ would equal its true value $f_{2}$ and $Q$ would equal its true value $q$. According to the law of propagation of errors (e.g., see Mandel ${ }^{25}$ ) and provided that the relative errors $\Delta A_{k}(k=0,1,2)$ are small, the following is approximately valid:

$$
\begin{gathered}
F_{2}=f_{2}\left(1-\Delta A_{2}+\Delta A_{0}\right) \\
Q=q\left(1+\Delta A_{1}-\Delta A_{2}\right)
\end{gathered}
$$

A given set of independent measurement pairs

$$
F_{2 i}, Q_{i} \quad i=1, \ldots, m
$$

has the statistical properties ( $\mathbb{E}$ denotes expectation):

$$
\begin{array}{rll}
\mathbb{E} F_{2 i}=f_{2 i} & \text { and } & \sigma^{2}\left(F_{2 i}\right)=\left[\left(\lambda_{0 i}\right)^{2}+\left(\lambda_{2 i}\right)^{2}\right] \cdot\left(f_{2 i} \sigma\right)^{2} \\
\mathbb{E} Q_{i}=q_{i} & \text { and } & \sigma^{2}\left(Q_{i}\right)=\left[\left(\lambda_{1 i}\right)^{2}+\left(\lambda_{2 i}\right)^{2}\right] \cdot\left(q_{i} \sigma\right)^{2}
\end{array}
$$

$F_{2 i}$ and $Q_{i}$ are dependent because of the common error term $\Delta A_{2 i}$. Their covariance is equal to

$$
\sigma\left(F_{2 i}, Q_{i}\right):=\mathbb{E}\left\{\left(F_{2 i}-f_{2 i}\right) \cdot\left(Q_{i}-q_{i}\right)\right\}=f_{2 i} q_{i}\left(\lambda_{2 i} \sigma\right)^{2}
$$

The coefficient of correlation of $F_{2 i}$ and $Q_{i}$ is given by

$$
\begin{aligned}
\rho_{i}: & =\frac{\sigma\left(F_{2 i}, Q_{i}\right)}{\sigma\left(F_{2 i}\right) \cdot \sigma\left(Q_{i}\right)} \\
& =\left\{\left[1+\left(\frac{\lambda_{0 i}}{\lambda_{2 i}}\right)^{2}\right] \cdot\left[1+\left(\frac{\lambda_{1 i}}{\lambda_{2 i}}\right)^{2}\right]\right\}^{-0.5}
\end{aligned}
$$

Equations (10) and (11) follow directly from eqs. (8) and (9).

\section{The Algorithm}

Define

$$
S\left(\beta ; q_{1}, \ldots, q_{m}\right):=\sum_{i=1}^{m}\left[\frac{\left(\Delta F_{2 i}\right)^{2}+\left(\Delta Q_{i}\right)^{2}-2 \rho_{i} \Delta F_{2 i} \Delta Q_{i}}{1-\rho_{i}{ }^{2}}\right]
$$

where

$$
\Delta F_{2 i}:=\frac{F_{2 i}-H\left(q_{i}, \beta\right)}{\sigma\left(F_{2 i}\right)} \cdot \sigma
$$

and

$$
\Delta Q_{i}:=\frac{Q_{i}-q_{i}}{\sigma\left(Q_{i}\right)} \cdot \sigma
$$

An estimate $\hat{\beta}$ for $\beta$, which takes into account the error structure defined by eqs. (10) and (11), follows from 


$$
S\left(\hat{\beta} ; \hat{q}_{1}, \ldots, \hat{q}_{m}\right)=\min _{\beta ; q_{1}, \ldots, q_{m}} S\left(\beta ; q_{1}, \ldots, q_{m}\right)
$$

The unknown $f_{2 i}$ and $q_{i}$ may be replaced by the observed $F_{2 i}$ and $Q_{i}$ in the expressions (10) for the variances because the relative errors are known to be small. ${ }^{21}$ This simplifies the computation of eq. (13) considerably.

Criterion (13) is the maximum-likelihood criterion for the estimation of $\beta$ if we assume that $F_{2 i}$ and $Q_{i}$ are distributed according to a bivariate normal distribution with means and variances given by eqs. (10) and (11). Figure 3 shows a typical contour of the density of $\Delta F_{2}$ and $\Delta Q$. Other density contours vary only in size. If $\rho>0$, deviations in the direction $\Delta F_{2}=-\Delta Q$ are less probable than deviations of equal magnitude in the direction $\Delta F_{2}=\Delta Q$. Criterion (13) amounts to a minimization of the sum of squares of weighted residuals. For each pair $\left(F_{2 i}, Q_{i}\right)$ the residuals along the principle axes of the contour ellipse are evaluated, and the corresponding weights are inversely proportional to the length of the axes. Therefore

$$
S\left(\beta ; q_{1}, \ldots, q_{m}\right) \equiv \frac{1}{2} \sum_{i=1}^{m}\left[\frac{\left(\Delta F_{2 i}-\Delta Q_{i}\right)^{2}}{1-\rho_{i}}+\frac{\left(\Delta F_{2 i}+\Delta Q_{i}\right)^{2}}{1+\rho_{i}}\right]
$$

From this equation it can easily be derived that criterion (13) amounts to a minimization of the sum of squares of normal distances, proposed by Joshi, ${ }^{8}$ only if $F_{2 i}$ and $Q_{i}$ are independent (i.e., $\rho_{i}=0$ ), with common variance [i.e., $\sigma^{2}\left(F_{2 i}\right)$ $=\sigma^{2}\left(Q_{i}\right)=\sigma^{2}$ ] for all $i$. The number of unknowns in eq. (13) is $m+p$, where $p$ is the size of vector $\beta$. Standard nonlinear least-squares algorithms, for instance described by Powell, ${ }^{26}$ tend to break down for large values of $m$ because of large computation times and computer storage problems. An efficient algorithm for the solution of eq. (13), described by Linssen, ${ }^{27}$ is based on the special feature that $Q_{i}$ and $F_{2 i}$ contain information only on $q_{i}$ and $\beta$ and not on $q_{t}(t \neq i)$. The least-squares problem (13) with $m+p$ unknowns is reduced to a least-squares problem with $p$ unknowns by eliminating the $q_{i}$ 's in each iteration step. A user's manual $^{28}$ for an ALGOL procedure to tackle problems like eq. (13) is available from the second author.

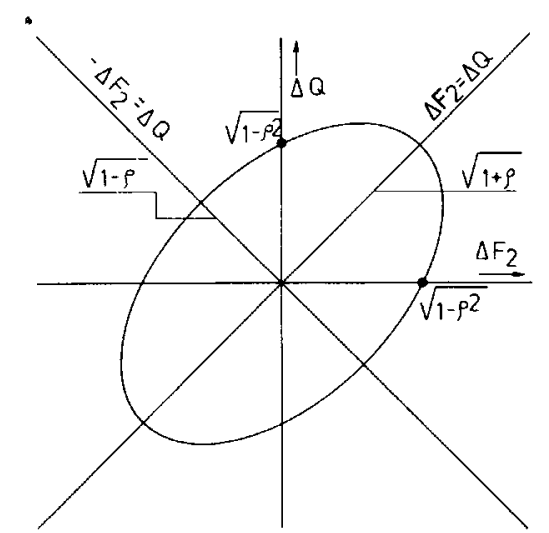

Fig. 3. Contours of the bivariate normal distribution of the measured variables $\Delta F_{2}$ and $\Delta Q$ with correlation coefficient $\rho$. 


\section{Accuracy of the Parameter Estimates}

The accuracies of the parameter estimates are approximated by a method based on the matrix of partial derivatives of the model function $H$, reported by Behnken. 9 This matrix has to be modified because of the recognition of observational errors in the measurement of both variables, namely, the degree of conversion $f_{2}$ as well as the monomer feed ratio $q$, instead of $f_{2}$ alone. Define the matrix with elements

$$
J_{i j}:=\delta_{i} \frac{\partial H(q, \beta)}{\partial \beta_{j}} \quad(i=1, \ldots, m ; j=1, \ldots, p)
$$

where

$$
\delta_{i}:=\frac{\left[1-\rho_{i}^{2}+\left(\gamma_{i}-\rho_{i}\right)^{2}\right]^{-0.5}}{\sigma\left(F_{2 i}\right)} \cdot \sigma
$$

and

$$
\gamma_{i}:=\frac{\sigma\left(Q_{i}\right)}{\sigma\left(F_{2 i}\right)} \cdot \frac{\partial H(q, \beta)}{\partial \dot{q}}
$$

The derivatives are evaluated in $\beta=\hat{\beta}$ and $q=\hat{q}_{i}$. The covariance matrix for $\hat{\beta}$ is approximated by

$$
\left(J^{T} J\right)^{-1} \sigma^{2}
$$

If $\delta_{i}=1$, eq. (14) is equivalent to Behnken's formula (15). ${ }^{9}$ A consistent estimate for $\sigma^{2}$ is given by

$$
\frac{S\left(\hat{\beta} ; \hat{q}_{1}, \ldots, \hat{q}_{m}\right)}{m-p}
$$

where $m-p$ is the number of degrees of freedom. The covariance matrix given by eq. (14) is a first-order approximation, which means that this matrix has been derived by assuming that $H$ can be written as its own first-order Taylor expansion around $\hat{\beta}$ and $\hat{q}$. This assumption is (almost) satisfied because the relative measurement errors are small.

\section{APPLICATION OF THE NEW CALCULATION METHOD}

First it must be mentioned that the proposed estimation procedure, presented in the preceding section, can replace the estimation step in the FCA-A and FCA-B procedures. ${ }^{4,21}$ To prevent any possible confusion the improved computation procedures originating from the $\mathrm{A}$ and $\mathrm{B}$ procedures ${ }^{4,21}$ are referred to as the "improved curve-fitting I/intersection" and the "improved curve-fitting I" procedure, respectively.

The performance of these new procedures is illustrated for the experimental data resulting from the vinyl acetate $\left(M_{1}\right)$-vinyl propionate $\left(M_{2}\right)$, free-radical copolymerization, ${ }^{*}$ with tert-butyl alcohol as solvent, at $62^{\circ} \mathrm{C}$ and $35 \mathrm{~kg} / \mathrm{cm}^{2}$. A total number of 260 GLC observations from 10 kinetic experiments, starting from different monomer feed compositions, is available for calculation. Experimental details are summarized in Table II.

* R. van der Meer and A. L. German, to be published with other vinyl acetate-vinyl ester copolymerizations. 


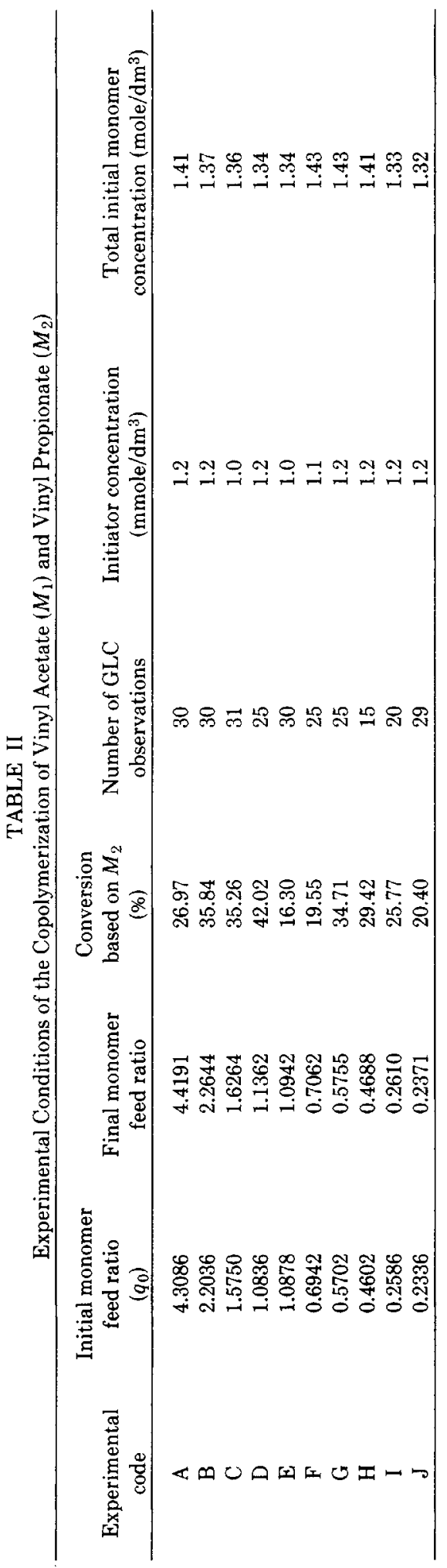


A detailed and critical consideration of the peak area repeatability has been carried out by German. ${ }^{21,24}$ Variations in sample size, column oven temperature, carrier gas flow, detector sensitivity, and electronic integrator contributed to a measurement error in the observed peak areas. For the binary system described the errors appeared to amount ${ }^{21}$ to $1.0,1.0$, and $1.5 \%$ for monomer $M_{1}$, monomer $M_{2}$, and the solvent. These relative errors are also supposed to be independent of the degree of conversion to copolymer; thus $\lambda_{0 i}=1.5, \lambda_{1 i}=1.0$, and $\lambda_{2 i}=1.0$ have been used in eqs. (10) and (11). The estimates of $\beta\left[=r_{1}, r_{2}\right.$, and $\left.q_{0 j}(j=1, \ldots, 10)\right]$ in eq. (13) are obtained by electronic computer (Burroughs 7700) and are compared with those resulting from the FCA-B procedure. 4,2I $^{2}$ The computed reactivity ratios, shown in Table III, demonstrate that in VAc-VP copolymerization, in which the correct $r$ values should be close to unity, the calculated values change dramatically by taking into account experimental errors in both measured variables. Such a large effect may indeed be expected because it can be derived from Figure 2 that when $q$ is almost constant with varying $f_{2}$, a small error in $q$ (distance $b$ ) will produce a large difference between observed and calculated degrees of conversion (distance $a$ ). It is evident that in such cases the $r$ values calculated by the FCA-B procedure are unreliable and that the standard deviations are overestimated. On the other hand, in copolymerizations in which the monomer feed ratio changes more rapidly with increasing degree of conversion, for instance when the $r$ values deviate more strongly from unity, the differences between FCA-B and the improved curvefitting I procedures may be expected to become less striking. The latter conclusion is confirmed by the second example in Table III, namely, the ethylenevinyl acetate copolymerization (with the same error structure assumed for the first example), of which the $r$ values ${ }^{4,21}$ calculated by the FCA-B procedure only slightly deviate from those calculated ${ }^{29}$ by the improved-curve-fitting I procedure. Even small changes, however, have become important in comparative studies, as, for example, in the investigation of the effect of pressure on the ethylene-vinyl acetate copolymerization ${ }^{30}$ and in the study on the reactivity of a homologous series of vinyl esters with ethylene as reference monomer..$^{29}$

Theoretically, the computed $r$ values will be insensitive to reindexation when the error structure, given by eqs. (10) and (11), corresponds to experimental reality. The differences between the $r$ values before and after reindexation (Table III) indeed appear to be small, compared with the calculated standard deviations. It is surprising that this also holds for the FCA-B results. From these findings it may be concluded that insensitivity to reindexation is a poor method of deciding whether the real-error structure has been taken into account.

Repeated GLC observations of a nonchanging copolymerization reaction mixture, performed when using a high-pressure copolymerization technique recently developed, ${ }^{6}$ demonstrate that the density contour of the observations agrees fairly well with the predicted shape (see Fig. 2).

The residuals [observed $\left.\left(F_{2 i}, Q_{i}\right)\right]$ minus [computed $\left.\left(f_{2 i}, q_{i}\right)\right]$ tend to have a direction corresponding to the longest principle axis of an elliptic density contour because, according to criterion (13), the weight attached to deviations along an axis is inversely proportional to its length.

The improved curve-fitting I/intersection procedure permits the calculation of the relation between $r_{1}$ and $r_{2}$ for each kinetic experiment. The changes in this procedure with respect to the FCA-A procedure ${ }^{21}$ are completely analogous 


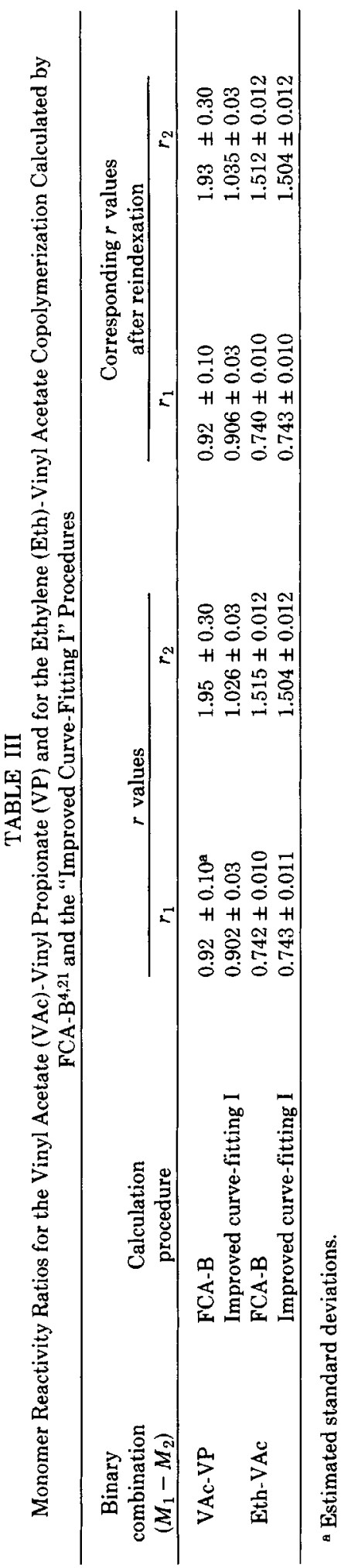




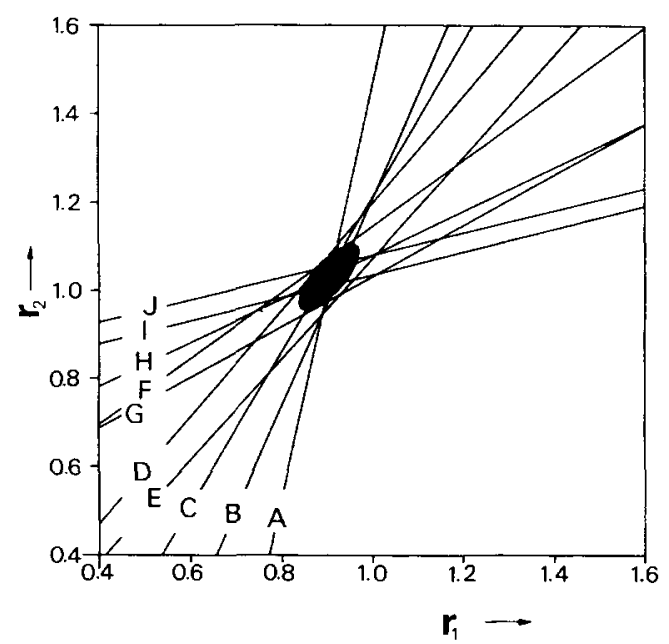

Fig. 4. Relations between $r_{1}$ and $r_{2}$ for the vinyl acetate $\left(M_{1}\right)$-vinyl propionate $\left(M_{2}\right)$ copolymerization according to the "improved curve-fitting $I /$ intersection" method, and the confidence region for $\alpha$ (confidence level) $=95 \%$ with regard to the $r$ values resulting from the "improved curve-fitting I" procedure.

to those introduced in the improved curve-fitting I procedure with respect to the FCA-B procedure. The improved curve-fitting $\mathrm{I} /$ intersection procedure is also based on the computation of eq. (13), but only two parameters, $r_{2}$ and $q_{0}$, are calculated repeatedly for a corresponding number of arbitrarily chosen values of $r_{1}$. The resulting almost straight curves are shown in Figure 4 for the vinyl acetate-vinyl propionate copolymerization.

A curve pertaining to a kinetic experiment with an incidental error of unknown origin will show up in a plot like Figure 4 because it will not intersect the area around the center of gravity of the majority of the intersection points. Moreover, other systematic deviations, possibly caused by an unsatisfactory copolymer equation, ${ }^{2,3}$ may show up in an intersection-point $\mathrm{drift}^{22}$ as the monomer feed composition changes. The plotted elliptic confidence region for $\alpha=95 \%$ in Figure 4 is crossed by almost all lines, which indicates that the calculated standard deviations for the $r$ values computed with the improved curve-fitting I procedure (Table III), are acceptable.

Furthermore, a test of the validity of a particular copolymerization scheme becomes possible under the conditions required for the approximation in eq. (14). This is illustrated and applied in a forthcoming paper. ${ }^{22}$

It must be emphasized that the present method of accounting for the measurement errors can be applied to other existing procedures; for example, the curve-fitting $D$ procedure ${ }^{10}$ in which both variables also contain a measurement error. This improvement on the curve-fitting $D$ procedure leads similarly to more accurate $r$ values, especially in copolymerization systems with one high and one low reactive monomer, shown by the large distance $(b)$, observation (2), Figure 1.

Finally, considering the errors in both measured variables, it may be concluded that the proposed novel algorithm will yield more accurate monomer reactivity ratios, which is of theoretical as well as practical importance. The present improvement will contribute to a more justified and accurate comparison of copolymerization data and to a meaningful evaluation of more detailed model 
descriptions. As a consequence it may support a better understanding of the physical and chemical-mechanistic aspects of copolymerization reactions.

We gratefully acknowledge the contribution of E. H. M. van Gorp to the implementation of the proposed method in the computer programs. The valuable comments of Professor Dr. R. Doornbos are also highly appreciated.

\section{References}

1. T. Alfrey, Jr., and G. Goldfinger, J. Chem. Phys., 12, 205 (1944).

2. F. R. Mayo and F. M. Lewis, J. Am. Chem. Soc., 66, 1594 (1944).

3. H. J. Harwood, N. W. Johnston, and H. Piotrowski, in The Computer in Polymer Science (J. Polym. Sci. Part C, 25), J. B. Kinsinger, Ed., Interscience, New York, 1968, p. 23; D. R. Montgomery and C. E. Fry, ibid, p. 59; G. R. Brown and J. G. Byrne, Polymer, 10, 333 (1969); R. H. Wiley, S. P. Rao, J.-I. Jin, and K. S. Kim, J. Macromol. Sci. Chem., A4, 1453 (1970); A. Rudin and R. G. Yule, J. Polym. Sci. A-1, 9, 3009 (1971).

4. A. L. German and D. Heikens, J. Polym. Sci. A-1, 9, 2225 (1971).

5. A. Guyot, C. Blanc, J. C. Daniel, and Y. Trambouze, C. R. Acad. Sci., 253, 1795 (1961); H. J. Harwood, H. Biakowitz, and H. F. Trommer, Polym. Prepr., 4, 133 (1963); H. K. Johnston and A. Rudin, J. Paint Technol., 42, 429 (1970); H. Narita, Y. Hoshii, and S. Machida, Angew. Makromol. Chem., 52, 117 (1976).

6. R. van der Meer and A. L. German, J. Polym. Sci. Polym. Chem. Ed., submitted.

7. P. W. Tidwell and G. A. Mortimer, J. Macromol. Sci. Rev. Macromol. Chem., C4, 281 (1970).

8. R. M. Joshi, J. Macromol. Sci. Chem., A7, 1231 (1973).

9. D. W. Behnken, J. Polym. Sci. Part A, 2, 645 (1964).

10. P. W. Tidwell and G. A. Mortimer, J. Polym. Sci. Part A, 3, 369 (1965).

11. J. Schaefer, J. Phys. Chem., 70, 1975 (1966).

12. N. Jaacks, Makromol. Chem., 105, 289 (1967); ibid., 161, 161 (1972).

13. M. Fineman and S. D. Ross, J. Polym. Sci., 5, 259 (1950).

14. A. J. Yezrielev, E. L. Brokhina, and Y. S. Roskin, Vysokomol. Soedin., A11, 1670 (1969).

15. T. Kelen and F. Tüdös, J. Macromol. Sci. Chem., A9, 1, (1975).

16. R. M. Joshi and S. L. Kapur, J. Polym. Sci., 14, 508, (1954).

17. R. M. Joshi and S. G. Joshi, J. Macromol. Sci. Chem., A5, 1329 (1971).

18. C. Tosi, Eur. Polym. J., 9, 357 (1973).

19. T. K. Wu, J. Phys. Chem., 73, 1801 (1969); J. Polym. Sci. A-2, 8, 167 (1970).

20. T. Alfrey, Jr., J. J. Bohrer, and H. Mark, Copolymerization, Interscience, New York, 1952, pp. 8-23.

21. A. L. German, Ph.D. Thesis, Eindhoven University of Technology, 1970.

22. R. van der Meer, J. M. Alberti, A. L. German, and H. N. Linssen, J. Polym. Sci. Polym. Chem. Ed., submitted.

23. H. O. Hartley, Technometrics, 3, 269 (1961).

24. A. L. German and D. Heikens, Anal. Chem., 43, 1940 (1971).

25. J. Mandel, The Statistical Analysis of Experimental Data, Wiley, New York, 1964; p. 74.

26. M. J. D. Powell, in Numerical Methods for Unconstrained Optimization, W. Murray, Ed., Academic, London, 1972, Chap. III.

27. H. N. Linssen, Nonlinear Regression with Nuisance Parameters: An Algorithm to Estimate the Parameters, Proceedings 1st European Meeting of Statisticians, Grenoble, 1976, North Holland, Amsterdam, 1977.

28. H. N. Linssen, Regression with Nuisance Parameters, User's Manual, Internal Report, COSOR-Note R 76-17, Eindhoven University of Technology, Eindhoven, The Netherlands, 1976.

29. R. van der Meer, E. H. M. van Gorp, and A. L. German, J. Polym. Sci. Polym. Chem. Ed., 15, 1489 (1977).

30. R. van der Meer, A. L. German, and D. Heikens, J. Polym. Sci. Polym. Chem. Ed., 15, 1765 (1977).

Received May 5, 1977 